\title{
PERBANDINGAN REGRESI BINOMIAL NEGATIF DAN REGRESI GENERALISASI POISSON DALAM MENGATASI OVERDISPERSI (Studi Kasus: Jumlah Tenaga Kerja Usaha Pencetak Genteng di Br. Dukuh, Desa Pejaten)
}

\author{
Ni Made Rara Keswari ${ }^{\S 1}$, I Wayan Sumarjaya ${ }^{2}$, Ni Luh Putu Suciptawati ${ }^{3}$ \\ ${ }^{1}$ Jurusan Matematika, Fakultas MIPA - Universitas Udayana [Email: rarakeswari@ gmail.com] \\ ${ }^{2}$ Jurusan Matematika, Fakultas MIPA - Universitas Udayana [Email: sumarjaya@unud.ac.id] \\ ${ }^{3}$ Jurusan Matematika, Fakultas MIPA - Universitas Udayana [Email: putusuciptawati@yahoo.co.id] \\ ${ }^{\S}$ Corresponding Author
}

\begin{abstract}
Poisson regression is a nonlinear regression that is often used to model count response variable and categorical, interval, or count regressor. This regression assumes equidispersion, i.e., the variance equals the mean. However, in practice, this assumption is often violated. One of this violation is overdispersion in which the variance is greater than the mean. There are several methods to overcome overdispersion. Two of these methods are negative binomial regression and generalized Poisson regression. In this research, binomial negative regression and generalized Poisson regression statistically equally good in handling overdispersion.
\end{abstract}

Keyword: Poisson Regression, Overdispersion, Negative Binomial Regression, Generalized Poisson Regression.

\section{PENDAHULUAN}

Analisis regresi merupakan suatu metode yang digunakan untuk memprediksi nilai satu peubah berdasarkan nilai peubah yang lain. Peubah yang diprediksi dinyatakan sebagai peubah terikat, sedangkan peubah yang memprediksi dinyatakan sebagai peubah bebas. Analisis regresi dibedakan atas analisis regresi linear dan analisis regresi nonlinear. Analisis regresi linear, memiliki parameter yang linear, dan menyebar normal. Apabila data dari peubah terikat yang hendak dianalisis tidak menyebar normal dan tidak linear secara parameter, maka analisis regresi yang digunakan adalah analisis regresi nonlinear. Memodelkan data pada analisis regresi nonlinear dapat menggunakan Generalized Linear Model (GLM).

Terdapat tiga komponen utama dari GLM yaitu komponen acak, komponen sistematis, dan fungsi penghubung (link function) (Agresti [1]). Salah satu analisis regresi nonlinear yang dimodelkan dengan GLM adalah analisis regresi Poisson. Analisis regresi Poisson digunakan ketika data dari peubah terikat yang akan dianalisis berupa data cacah, dan peubah bebasnya berupa data kategorik, interval, ataupun cacah. Pada penerapannya, analisis regresi Poisson harus memenuhi asumsi ekuidispersi (equidispersion). Asumsi ekuidispersi adalah asumsi nilai ragam dan rata-rata data yang sama. Pemenuhan asumsi ekuidispersi pada regresi Poisson mengakibatkan model regresi yang terbentuk hanya menyertakan parameter regresi. Pada praktiknya, sering terjadi perbedaan nilai ragam dan rata-rata pada data. Perbedaan nilai ragam dan rata-rata data salah satunya mengindikasikan adanya kondisi overdispersi. Kondisi overdispersi adalah 
kondisi ragam yang lebih besar dari rata-rata data. Apabila data dengan kondisi overdispersi tetap dianalisis menggunakan analisis regresi Poisson, maka akan ada informasi yang hilang akibat tidak termodelkannya parameter dispersi dalam model regresi yang terbentuk. Parameter dispersi adalah parameter yang muncul akibat tidak terjadinya kondisi ekuidispersi. Terdapat banyak metode regresi yang dapat digunakan untuk mengatasi kasus overdispersi, dua di antaranya adalah regresi binomial negatif dan regresi generalisasi Poisson.

Kata mengatasi overdispersi pada regresi binomial negatif dan regresi generalisasi Poisson bermakna bahwa kedua metode analisis regresi ini dapat mengakomodasi overdispersi. Mengakomodasi overdispersi oleh regresi binomial negatif dan regresi generalisasi Poisson yaitu kedua metode regresi ini dapat memodelkan data yang mengalami overdispersi tanpa harus menghilangkan kondisi overdispersi dari data tersebut. Regresi binomial negatif sebagai regresi yang berdistribusi gabungan antara distribusi Poisson-gamma, dan regresi generalisasi Poisson sebagai pengembangan dari regresi Poisson dengan mengasumsikan model regresinya berdistribusi generalisasi Poisson dapat memodelkan data yang mengalami overdispersi karena pada model regresi yang terbentuk dari kedua metode analisis ini dapat menyertakan parameter regresi sekaligus parameter dispersi.

Studi kasus yang akan digunakan dalam penelitian ini adalah jumlah tenaga kerja usaha pencetak genteng di Br. Dukuh, Pejaten. Tenaga kerja usaha pencetak genteng adalah pekerja yang bekerja pada pemilik usaha pencetak genteng dengan pekerjaan meliputi mengolah tanah menjadi siap untuk dicetak, mencetak tanah menjadi genteng, dan memproses genteng sehingga siap untuk dijual. Data dari jumlah tenaga kerja usaha pencetak genteng merupakan data cacah, sehingga tepat digunakan pada penelitian ini.

Jumlah tenaga kerja usaha pencetak genteng dapat dipengaruhi oleh jumlah bahan baku tanah liat, luas lokasi usaha pencetak genteng, kapasitas tungku pembakaran genteng, jumlah mesin cetak genteng, dan lokasi usaha pencetak genteng. Dari kelima hal yang dapat memengaruhi jumlah tenaga kerja usaha pencetak genteng, peneliti hanya menggunakan kapasitas tungku pembakaran genteng, jumlah mesin cetak genteng, dan lokasi usaha pencetak genteng saja. Peneliti hanya menggunakan kapasitas tungku pembakaran genteng, jumlah mesin cetak genteng, dan lokasi usaha pencetak genteng karena ketiga hal tersebut dapat mewakili luas lokasi usaha pencetak genteng dan jumlah bahan baku tanah liat.

Data jumlah bahan baku tanah liat telah terwakili oleh kapasitas tungku pembakaran genteng. Luas usaha pencetak genteng telah terwakili oleh jumlah mesin pencetak genteng. Semakin banyak jumlah mesin pencetak genteng, maka lokasi usaha pencetak genteng juga semakin luas. Pemilik usaha pencetak genteng tidak akan memperbanyak jumlah mesin pencetak genteng jika lokasi usahanya juga tidak diperluas karena genteng perlu tahap pengeringan dengan dijemur di bawah terik matahari. Jika genteng tidak dijemur di bawah terik matahari, maka genteng akan pecah saat pembakaran.

Berdasarkan pemaparan di atas, peneliti ingin menggunakan regresi binomial negatif dan regresi generalisasi Poisson untuk mendapatkan model regresi terbaik dari jumlah tenaga kerja usaha pencetak genteng berdasarkan tiga peubah bebas antara lain jumlah mesin pencetak genteng, lokasi usaha pencetak genteng, dan kapasitas tungku pembakaran genteng.

Tujuan dari penelitian ini adalah untuk mendapatkan model regresi jumlah tenaga kerja usaha pencetak genteng yang terbentuk dari analisis regresi binomial negatif dan analisis regresi generalisasi Poisson; untuk menentukan peubah manakah yang secara nyata dapat memprediksikan jumlah tenaga kerja yang direkrut pengrajin genteng berdasarkan analisis regresi binomial negatif dan analisis regresi generalisasi Poisson; untuk menentukan model regresi terbaik antara analisis regresi binomial negatif dan analisis regresi generalisasi Poisson dalam memprediksikan jumlah tenaga kerja 
usaha pencetak genteng jika dilihat dari kriteria Akaike's Information Criterion (AIC) dan Bayesian Information Criterion (BIC).

\section{TINJAUAN PUSTAKA}

Pada tinjauan pustakan dibahas tentang analisis regresi, distribusi binomial negatif, distribusi generalisasi Poisson, model regresi untuk regresi binomial negatif dan regresi generalisasi Poisson, uji signifikansi dari masing-masing model regresi yang terbentuk, dan pengujian model terbaik.

\subsection{Analisis Regresi}

Analisis regresi merupakan suatu metode untuk memprediksikan nilai satu peubah berdasarkan nilai peubah yang lain. Peubah yang diprediksi dinyatakan sebagai peubah terikat $(Y)$ sedangkan peubah yang memprediksi dinyatakan sebagai peubah bebas $(X)$. Peubah yang diprediksi dinyatakan sebagai peubah terikat karena nilainya ditentukan oleh peubah bebas. Peubah yang memprediksi dinyatakan sebagai peubah bebas karena nilainya dapat dikontrol. Secara umum, model dari analisis regresi dapat dinyatakan sebagai berikut:

$$
\begin{aligned}
Y= & \beta_{0}+\beta_{1} X_{1}+\beta_{2} X_{2}+\cdots+\beta_{k-1} X_{k-1}+ \\
& \beta_{k} X_{k}+\varepsilon,
\end{aligned}
$$

dengan $\beta_{0}, \beta_{1}, \beta_{2}, \beta_{k-1}, \ldots, \beta_{k}$ merupakan nilai yang belum diketahui (parameter) dan harus diduga, sedangkan $\varepsilon$ melambangkan sisaan.

Analisis regresi dapat dibedakan atas analisis regresi linear dan analisis regresi nonlinear. Penerapan analisis regresi linear harus memenuhi asumsi kelinearan dalam parameter dan berdistribusi normal. Apabila model regresi dari data yang dianalisis tidak linear secara parameter dan tidak berdistribusi normal, maka analisis regresi yang digunakan adalah analisis regresi nonlinear. Memodelkan data yang tidak linear secara parameter dapat menggunakan Generalized Linear Model (GLM).
Kata generalized merujuk pada distribusi dari $Y$ yang tidak diasumsikan normal. Terdapat tiga komponen utama dari GLM yaitu: komponen acak, komponen sistematis, dan fungsi penghubung (link function) (Agresti [1]).

\subsection{Distribusi Binomial Negatif}

Distribusi binomial negatif yang digunakan pada penilitian ini merupakan distribusi binomial negatif sebagai distribusi campuran Poisson-gamma. Distribusi gamma dapat mengakomodasi overdispersi pada regresi Poisson karena tidak mengasumsikan kondisi ekuidispersi pada penerapannya.

Distribusi binomial negatif dinyatakan sebagai berikut (Hilbe [3]):

$$
\begin{gathered}
f(y ; \mu, \alpha)=\frac{\Gamma\left(y_{i}+1 / \alpha\right)}{\Gamma\left(y_{i}+1\right) \Gamma(1 / \alpha)}\left(\frac{1}{1+\alpha \mu}\right)^{\frac{1}{\alpha}} \\
\left(1-\frac{1}{1+\alpha \mu}\right)^{y_{i}} .
\end{gathered}
$$

Distribusi binomial negatif memiliki rata-rata $\mu$ dan ragam $\mu+\alpha \mu^{2}$ (Hilbe [3]).

Apabila terjadi kondisi ekuidispersi, atau parameter dispersi $\alpha=0$ maka distribusi binomial negatif kembali ke bentuk distribusi Poisson sebagai berikut:

$$
\begin{aligned}
f(y ; \mu, \alpha) & =\frac{\Gamma\left(y_{i}+r\right)}{\Gamma\left(y_{i}+1\right) \Gamma(r)}\left(\frac{1}{1+\frac{\mu}{r}}\right)^{r}\left(\frac{r \mu}{1+r \mu}\right)^{y_{i}} \\
& =\frac{\Gamma\left(y_{i}+r\right)}{\mathrm{y} ! \Gamma(r)}\left(\frac{1}{1+\frac{\mu}{r}}\right)^{r}\left(\frac{\mu}{r+\mu}\right)^{y_{i}} \\
& =\frac{\Gamma\left(y_{i}+r\right)}{\Gamma(r)(r+\mu)^{y_{i}}} \frac{\mu^{y_{i}}}{y !} \frac{1}{\left(1+\frac{\mu}{r}\right)^{r}} \\
& =1 \frac{\mu^{y_{i}}}{y !} \frac{1}{e^{\mu}} \\
& =\frac{\mu^{y_{i}}}{y !} e^{-\mu}, \text { dengan } r=\frac{1}{\alpha}=\infty .
\end{aligned}
$$

\subsection{Distribusi Generalisasi Poisson}

Distribusi generalisasi Poisson merupakan pengembangan dari distribusi Poisson. Suatu peubah terikat $Y$ yang berdistribusi generalisasi Poisson memiliki fungsi distribusi sebagai berikut (Famoye [2]):

$f(y ; \mu, \alpha)=$ $\left(\frac{\mu}{1+\alpha \mu}\right)^{y} \frac{(1+\alpha y)^{y-1}}{y !} \exp \left[\frac{-\mu(1+\alpha y)}{1+\alpha \mu}\right]$, 
nilai rata - rata $\mu$ dan ragam $\mu(1+\alpha \mu)^{2}$.

Apabila terjadi kondisi ekuidispersi, atau $\alpha=0$ maka distribusi generalisasi Poisson kembali ke bentuk distribusi Poisson sebagai berikut:

$$
\begin{aligned}
& f(y ; \mu, \alpha)= \\
& \begin{aligned}
\left(\frac{\mu}{1+0 \mu}\right)^{y} \frac{(1+0 y)^{y-1}}{y !} \exp \left[\frac{-\mu(1+0 y)}{1+0 \mu}\right] \\
=\frac{\mu^{y}}{y !} \exp [-\mu] .
\end{aligned}
\end{aligned}
$$

\subsection{Analisis Regresi Binomial Negatif}

Regresi binomial negatif (RBN) berdistribusi binomial negatif untuk memodelkan data cacah yang mengalami kondisi ekuidispersi maupun yang mengalami overdispersi.

RBN menggunakan model GLM dengan fungsi penghubung log yang diasumsikan memiliki bentuk sebagai berikut:

$$
Y=\log \mu=\eta=x^{\prime} \beta .
$$

Pendugaan parameter $\beta_{0}, \beta_{1}, \beta_{2}, \beta_{k-1}, \ldots, \beta_{k}$ menggunakan Maximum Likelihood Estimator (MLE).

Fungsi likelihood $L(\mu ; y, \alpha)$ dan $\log$ likelihood $\mathcal{L}(\mu ; y, \alpha)$ dari persamaan dari distribusi binomial negatif dapat dinyatakan sebagai berikut (Hilbe [3]):

$$
\begin{gathered}
L(\mu ; y, \alpha)=\frac{\Gamma\left(y_{i}+1 / \alpha\right)}{\Gamma\left(y_{i}+1\right) \Gamma(1 / \alpha)}\left(\frac{1}{1+\alpha \mu}\right)^{\frac{1}{\alpha}} \\
\left(1-\frac{1}{1+\alpha \mu}\right)^{y_{i}} .
\end{gathered}
$$

Fungsi likelihood regresi binomial negatif disederhanakan dengan mencari fungsi log likelihood $\mathcal{L}(\mu ; y, \alpha)$ seperti pada persamaan berikut:

$$
\begin{aligned}
& \mathcal{L}(\mu ; y, \alpha)=\sum_{i=1}^{n} y_{i} \ln \left(\frac{\alpha \mu}{1+\alpha \mu}\right)- \\
& \frac{1}{\alpha} \ln 1+\alpha \mu+ \\
& \ln \Gamma\left(y_{i}+1 / \alpha\right)- \\
&\left.\ln \Gamma\left(y_{i}+1\right)-\ln \Gamma(1 / \alpha)\right\} .
\end{aligned}
$$

Fungsi log likelihood dapat dinyatakan kembali dengan mengganti $\mu=\exp \left(x^{\prime} \beta\right)$ sebagai berikut:

$$
\begin{gathered}
\mathcal{L}(\mu ; y, \alpha)=\sum_{i=1}^{n} y_{i} \ln \left(\frac{\alpha \exp (x, \beta)}{1+\alpha \exp \left(x^{\prime} \beta\right)}\right)- \\
\frac{1}{\alpha} \ln 1+ \\
\alpha \exp \left(x^{\prime} \beta\right)+ \\
\ln \Gamma\left(y_{i}+1 / \alpha\right)-\ln \Gamma\left(y_{i}+1\right)-
\end{gathered}
$$

$\ln \Gamma(1 / \alpha)$

Pendugaan parameter RBN menggunakan metode iteratively re-weighted least squares (IRLS). Metode IRLS dikenal sebagai metode Fisher scoring [3].

\subsection{Analisis Regresi Generalisasi Poisson}

Regresi Generalisasi Poisson (RGP) merupakan pengembangan dari regresi Poisson (RP). Peubah terikat $(Y)$ dari RGP berdistribusi generalisasi Poisson dengan fungsi distribusi sebagai berikut:

$$
\begin{gathered}
f(y ; \mu, \alpha)= \\
\left(\frac{\mu}{1+\alpha \mu}\right)^{y} \frac{(1+\alpha y)^{y-1}}{y !} \exp \left[\frac{-\mu(1+\alpha y)}{1+\alpha \mu}\right], \quad y= \\
0,1,2, \ldots
\end{gathered}
$$

Model regresi yang terbentuk dari analisis generalisasi Poisson menggunakan GLM dengan fungsi penghubung log sebagai berikut:

$$
Y=\log \mu=\eta=x^{\prime} \beta
$$

Pendugaan parameter pada RGP menggunakan MLE. Fungsi likelihood dari RGP adalah sebagai berikut:

$$
\begin{gathered}
L(\mu ; y, \alpha)=\prod_{i=1}^{n}\left\{\left(\frac{\mu}{1+\alpha \mu}\right)^{y} \frac{(1+\alpha y)^{y-1}}{y !}\right. \\
\left.\exp \left[\frac{-\mu(1+\alpha y)}{1+\alpha \mu}\right]\right\}
\end{gathered}
$$

Persamaan di atas dapat disederhanakan dengan mencari fungsi log likelihood $\mathcal{L}(\mu ; y, \alpha)$ seperti pada persamaan berikut:

$$
\begin{aligned}
\mathcal{L}(\mu ; y, \alpha)=\sum_{i=1}^{n}\left\{y_{i}[\ln \mu-\ln (1+\alpha \mu)]\right. \\
+(y-1) \ln (1+\alpha y)- \\
\ln y !+ \\
\left.\left(\frac{-\mu(1+\alpha y)}{1+\alpha \mu}\right)\right\}
\end{aligned}
$$

Memaksimumkan fungsi $\mathcal{L}(\mu ; y, \alpha)$ dapat dilakukan dengan mencari turunan terhadap masing-masing parameter $\beta$ dan $\alpha$ kemudian disamakan dengan nol. Parameter $\beta$ dimunculkan dengan mensubstitusi nilai $\mu=e^{\beta_{0}+\sum_{i=1}^{k} \beta_{k} X_{k}}$. 


\subsection{Uji Signifikansi Parameter Regresi \\ Binomial Negatif dan Regresi \\ Generalisasi Poisson}

Uji Signifikansi model diperlukan untuk melihat pengaruh dari peubah terikat yang disertakan dalam model. Uji signifikansi model dibedakan atas uji serentak dan uji parsial masing-masing peubah terikat.

Uji serentak terhadap signifikansi parameter RBN dan RGP dilakukan dengan menggunakan statistik uji rasio likelihood. Hipotesis ujinya sebagai berikut:

$H_{0}: \beta_{0}=\beta_{1}=\cdots=\beta_{j}=0$

$H_{1}$ : terdapat $\beta \neq 0 ; \quad j=0,2, \ldots, k$.

Statistik uji rasio likelihood adalah sebagai berikut [3]:

dengan

$$
L R=-2\left(\mathcal{L}_{\text {reduce }}-\mathcal{L}_{\text {full }}\right)
$$

$\mathcal{L}_{\text {reduce }}$ menyatakan nilai dugaan fungsi log likelihood setelah menstubtitusikan nilai taksiran parameter $\beta_{0}$ yang diperoleh dari taksiran model

$\log \left(\mu_{i}\right)=\beta_{0} \quad$ (model dengan intersep saja).

$\mathcal{L}_{\text {full }} \quad$ menyatakan nilai dugaan fungsi log likelihood setelah mensubstitusikan nilai-nilai taksiran parameter $\beta_{0}, \beta_{1}, \ldots, \beta_{k}$ yang diperoleh dari taksiran full model.

Aturan keputusannya adalah $H_{0}$ ditolak pada tingkat signifikansi $\alpha$ jika $L R$ lebih besar dari $\chi_{(\alpha, p)}^{2}$, dengan $p$ adalah $k$ parameter dari full model dikurangi $k$ parameter reduce model. Apabila tolak $H_{0}$ berarti minimal ada satu parameter yang signifikan pada model regresi yang terbentuk.

Uji parsial signifikansi parameter adalah uji untuk masing-masing parameter yang berpengaruh terhadap model yang terbentuk pada RBN dan RGP. Uji yang digunakan adalah uji Wald. Uji Wald memiliki hipotesis uji sebagai berikut [5]:

$H_{0}: \beta_{j}=0$ (pengaruh peubah ke- $j$ tidak signifikan)
$H_{1}: \beta_{j} \neq 0$ (pengaruh peubah ke- $j$ signifikan) statistik uji Wald adalah

$$
W=\left[\frac{\hat{\beta}_{j}}{s e \hat{\beta}_{j}}\right]^{2}
$$

dengan $\hat{\beta}_{j}$ dugaan parameter $\beta_{j}$ dan $s e \hat{\beta}_{j}$ merupakan dugaan standar error dari $\hat{\beta}_{j}$.

Kriteria pengujian statistik uji di atas adalah $H_{0}$ ditolak, jika $W>\chi_{(\alpha, 1)}^{2}$ dengan $\alpha$ adalah tingkat signifikansi dan derajat bebas 1. Apabila terjadi penolakan terhadap $H_{0}$ berarti parameter yang diuji signifikan atau memberikan pengaruh yang nyata terhadap $Y$.

\subsection{Pengujian Model Terbaik}

Pengujian model terbaik dilakukan untuk menentukan model terbaik antara model yang terbetuk dari RGP dan RBN yang dilihat dari nilai AIC dan BIC.

\subsubsection{Akaike's Information Criterion (AIC)}

AIC didefinisikan sebagai berikut:

$$
\mathrm{AIC}=-2(\mathcal{L}-k),
$$

dengan $\mathcal{L}$ adalah model $\log$ likelihood, dan $k$ adalah jumlah parameter pada model. Model dengan nilai AIC lebih kecil dipilih sebagai model terbaik untuk data [3].

\subsubsection{Bayesian Information Criterion (BIC)}

BIC didefinisikan sebagai berikut [3]:

$$
\mathrm{BIC}=-2 \mathcal{L}+k \ln (n),
$$

dengan $\mathcal{L}$ adalah model $\log$ likelihood, $k$ adalah jumlah parameter pada model, dan $n$ adalah jumlah peringkat kelas. Model dengan nilai BIC lebih kecil dipilih sebagai model terbaik untuk data.

\section{METODE PENELITIAN}

Pada penelitian ini, jenis data yang digunakan adalah data jumlah tenaga kerja usaha pencetak genteng $(Y)$, jumlah mesin pencetak genteng $\left(X_{1}\right)$, lokasi usaha pencetak genteng $\left(X_{2}\right)$, dan kapasitas tungku pembakaran genteng $\left(X_{3}\right)$. Sumber data pada penelitian ini adalah data primer karena diperoleh langsung dengan cara pencacahan 
ke masing-masing rumah warga di Br. Dukuh, Pejaten yang memiliki usaha pencetak genteng.

Adapun langkah-langkah analisis dalam penelitian ini adalah mendeskripsikan data jumlah tenaga kerja pencetak genteng pada masing-masing rumah warga di $\mathrm{Br}$. Dukuh, Pejaten yang memiliki usaha pencetak genteng untuk melihat apakah rata-rata dan ragam data mengalami overdispersi. Apabila terjadi overdispersi, maka data dianalisis dengan analisis regresi binomial negatif dan analisis regresi generalisasi Poisson. Setelah mendapatkan model regresi binomial negatif dan regresi generalisasi Poisson, maka langkah selanjutnya melakukan uji signifikansi parameter, kemudian menentukan model terbaik dalam menganalisis data yang mengalami overdispersi berdasarkan nilai AIC dan BIC. Setelah mendapatkan model terbaik maka langkah terakhir adalah interpretasi hasil yang didapat.

\section{HASIL DAN PEMBAHASAN}

Deskripsi dari jumlah tenaga kerja usaha pencetak genteng $(Y)$ yang diolah dengan menggunakan bantuan software MINITAB 14 adalah nilai minimum 0; nilai maksimum 14; rata-rata 3,432 ; ragam 12,363 ; dan banyaknya pengamatan adalah 37 . Rasio ragam berbanding rata-rata dari jumlah tenaga kerja usaha pencetak genteng adalah 3,6. Ragam dinyatakan mengalami overdispersi apabila nilai rasio antara ragam dan rata-rata lebih besar dari 2,5 (Indraswari [4]). Rasio ragam berbanding rata-rata dari jumlah tenaga kerja usaha pencetak genteng lebih besar dari 2,5 maka data jumlah tenaga kerja usaha pencetak genteng mengalami overdispersi. Karena $Y$ mengalami overdispersi, maka langkah selanjutnya adalah menganalisis data menggunakan analisis regresi binomial negatif dengan bantuan software SAS 9.2.

Model regresi binomial negatif diperoleh dari analisis data menggunakan bantuan software SAS 9.2 yaitu:

$$
\begin{aligned}
& \mu=\exp \left(-2,2850+0,3901 \mathrm{X}_{1}-0,2794 \mathrm{X}_{2}\right. \\
& \left.+0,2711 \mathrm{X}_{3}\right) .
\end{aligned}
$$

Setelah mendapatkan model regresi binomial negatif, maka selanjutnya dilakukan uji signifikansi parameter regresi dengan hasil dapat dilihat pada Tabel 1.

Tabel 1. Uji Signifikansi Parameter Regresi Binomial Negatif

\begin{tabular}{|c|c|c|c|}
\hline $\begin{array}{c}\text { Peubah } \\
\text { Bebas }\end{array}$ & $\begin{array}{l}\text { Koefisien } \\
(\beta)\end{array}$ & $\begin{array}{c}\text { Uji } \\
\text { Wald }\end{array}$ & P-Value \\
\hline Intercept & $-2,2850$ & 2,90 & 0,0884 \\
\hline $\mathrm{X}_{1}$ & 0,3901 & 47,33 & $<0,0001$ \\
\hline $\mathrm{X}_{2}$ & $-0,2794$ & 1,09 & 0,2958 \\
\hline $\mathrm{X}_{3}$ & 0,2711 & 4,38 & 0,0364 \\
\hline
\end{tabular}

Berdasarkan hasil yang didapat pada Tabel 1, maka hanya jumlah mesin pencetak genteng dan kapasitas tungku pembakaran genteng yang memiliki pengaruh nyata atau signifikan terhadap jumlah tenaga kerja usaha pencetak genteng di Br. Dukuh, Pejaten.

$\mu=\exp \left(-2,2850+0,3901 \mathrm{X}_{1}+\right.$ $\left.0,2711 X_{3}\right)$.

Interpretasi model yang terbentuk dari analisis regresi binomial negatif adalah apabila terjadi peningkatan sebesar satusatuan pada jumlah mesin pencetak genteng, maka jumlah tenaga kerja usaha pencetak genteng akan meningkat sebesar 47,71\%. Peningkatan sebesar $47,71 \%$ pada jumlah tenaga kerja usaha pencetak genteng karena terjadinya peningkatan jumlah mesin pencetak genteng sebesar satu-satuan ditunjukkan sebagai berikut:

$$
\begin{aligned}
100\left(e^{0,3901(1)}-1\right) \% & =100(1,4771-1) \% \\
& =47,71 \% .
\end{aligned}
$$

Peningkatan kapasitas tungku pembakaran genteng memiliki pengaruh positif terhadap jumlah tenaga kerja usaha pencetak genteng. Apabila terjadi peningkatan terhadap kapasitas tungku pembakaran genteng sebesar satu-satuan maka jumlah tenaga kerja usaha pencetak genteng akan meningkat sebesar 31,14\%. 
Peningkatan sebesar $31,14 \%$ dari jumlah tenaga kerja usaha pencetak genteng karena terjadi peningkatan sebesar satu-satuan pada kapasitas tungku pembakaran genteng ditunjukkan sebagai berikut:

$$
\begin{gathered}
100\left(e^{0,2711(1)}-1\right) \%= \\
=31,14 \% .
\end{gathered}
$$

Selanjutnya melakukan analisis regresi generalisasi Poisson pada data.

Model regresi yang terbentuk dari analisis regresi generalisasi Poisson menggunakan bantuan software SAS 9.2 adalah sebagai berikut:

$$
\begin{aligned}
& \mu=\exp \left(-2,2861+0,3896 \mathrm{X}_{1}-0,2743 \mathrm{X}_{2}\right. \\
& \left.\quad+0,2707 \mathrm{X}_{3}\right) .
\end{aligned}
$$

Setelah mendapatkan model regresi maka selanjutnya adalah melakukan uji signifikansi parameter regresi generalisasi Poisson dengan hasil uji dapat dilihat pada Tabel 2.

Tabel 2. Uji Signifikansi Parameter Regresi Generalisasi Poisson

\begin{tabular}{|c|l|c|c|}
\hline $\begin{array}{c}\text { Peubah } \\
\text { Bebas }\end{array}$ & $\begin{array}{l}\text { Koefisien } \\
(\beta)\end{array}$ & $\begin{array}{c}\mathrm{Uji} \\
\text { Wald }\end{array}$ & $P$-Value \\
\hline $\begin{array}{c}\text { Intercep } \\
t\end{array}$ & $-2,2861$ & $-1,72$ & 0,0948 \\
\hline$X_{1}$ & 0,3896 & 6,82 & $<0,0001$ \\
\hline$X_{2}$ & $-0,2743$ & $-1,01$ & 0,3178 \\
\hline$X_{3}$ & 0,2707 & 2,11 & 0,0423 \\
\hline
\end{tabular}

Berdasarkan hasil yang didapat pada Tabel 2, maka hanya jumlah mesin pencetak genteng dan kapasitas tungku pembakaran genteng yang memiliki pengaruh nyata atau signifikan terhadap jumlah tenaga kerja usaha pencetak genteng di Br. Dukuh, Pejaten.

$$
\begin{gathered}
\mu=\exp \left(-2,2861+0,3896 \mathrm{X}_{1}+\right. \\
\left.0,2707 \mathrm{X}_{3}\right) .
\end{gathered}
$$

Interpretasi model yang terbentuk adalah apabila terjadi peningkatan sebesar satu-satuan pada jumlah mesin pencetak genteng, maka jumlah tenaga kerja usaha pencetak genteng akan meningkat sebesar 47,63\%. Peningkatan sebesar 47,63\% pada jumlah tenaga kerja usaha pencetak genteng karena terjadinya peningkatan jumlah mesin pencetak genteng sebesar satu-satuan ditunjukkan sebagai berikut:

$$
\begin{aligned}
& 100\left(e^{0,3896(1)}-1\right) \%=100(1,4763-1) \% \\
& =47,63 \% \text {. }
\end{aligned}
$$
pembakaran genteng memiliki pengaruh positif terhadap jumlah tenaga kerja usaha pencetak genteng. Apabila terjadi peningkatan terhadap kapasitas tungku pembakaran genteng sebesar satu-satuan maka jumlah tenaga kerja usaha pencetak genteng akan meningkat sebesar 31,08\%. Peningkatan sebesar $31,08 \%$ dari jumlah tenaga kerja usaha pecetak genteng karena terjadi peningkatan sebesar satu-satuan pada kapasitas tungku pembakaran genteng ditunjukkan sebagai berikut:

$$
\begin{aligned}
100\left(e^{0,277(1)}-1\right) \% & =100(1,3108-1) \% \\
& =31,08 \% .
\end{aligned}
$$

Tahapan selanjutnya adalah melakukan pengujian model terbaik untuk membandingkan metode analisis yang lebih baik digunakan untuk mengatasi overdispersi. AIC dan BIC . Nili AIC dan BIC dapat dilihat pada Tabel 3.

Tabel 3. Nilai AIC dan BIC

\begin{tabular}{|c|c|c|}
\hline Regresi & AIC & BIC \\
\hline $\begin{array}{c}\text { Binomial } \\
\text { Negatif }\end{array}$ & 153,2045 & 161.2591 \\
\hline $\begin{array}{c}\text { Generalisasi } \\
\text { Poisson }\end{array}$ & 153,23 & 161,28 \\
\hline
\end{tabular}

Berdasarkan Tabel 3, nilai AIC dan BIC dari analisis regresi binomial negatif dan analisis regresi generalisasi Poisson hampir sama. Maka secara statistik, analisis regresi binomial negatif maupun analisis regresi generalisasi Poisson sama baiknya dalam menganalisis jumlah tenaga kerja usaha pencetak genteng di Br. Dukuh, Desa Pejaten. 


\section{SIMPULAN}

Menggunakan data jumlah tenaga kerja usaha pencetak genteng, jumlah mesin cetak genteng, lokasi usaha pencetak genteng, dan kapasitas tungku pembakaran genteng yang diolah dengan menggunakan software SAS 9.2, maka kesimpulan yang didapat dari penelitian ini adalah model regresi binomial negatif yaitu $\quad \mu=\exp (-2,2850+$ $\left.0,3901 \mathrm{X}_{1}+0,2711 \mathrm{X}_{3}\right)$.

Model regresi generalisasi Poisson yaitu $\mu=\exp \left(-2,2861+0,3896 \mathrm{X}_{1}+\right.$ $\left.0,2707 \mathrm{X}_{3}\right)$.

Berdasarkan uji signifikansi analisis regresi binomial negatif dan analisis regresi generalisasi Poisson, jumlah mesin pencetak genteng dan kapasitas tungku pembakaran genteng terbukti secara nyata memengaruhi jumlah tenaga kerja usaha pencetak genteng.

Berdasarkan pengujian model terbaik dengan kriteria AIC dan BIC, analisis regresi binomial negatif dan analisis regresi generalisasi Poisson sama baiknya dalam menganalisis jumlah tenaga kerja usaha pecetak genteng di Br. Dukuh, Desa Pejaten. 


\section{DAFTAR PUSTAKA}

[1] Agresti, A., 2002. Categorical Data Analysis. 2nd ed. New Jersey: John Wiley and Sons.

[2] Famoye, F., 1993. Restricted Generaized Poisson Regression Model.

Communications in Statistics - Theory and Methods, 22(5), pp.1335-54.

[3] Hilbe, J.M., 2011. Negative Binomial Regression. 2nd ed. New York: Cambridge University Press.

[4] Indraswari, M.S., 2011. Faktor-faktor Penyebab Kematian Bayi di Kabupaten Karangasem dengan Pendekatan Regresi Poisson. Skripsi. Denpasar: Jurusan Matematika Fakultas Matematika dan Ilmu Pengetahuan Alam Universitas Udayana.

[5] Myers, R.H., Montgomery, D.C., Vining, G.G. \& Robinson, T.J., 2010.

Generalized Linear Models with Applications in Engineering and Sciences. 2nd ed. New Jersey: John Wiley and Sons. 